\title{
Comunicação e Semiótica: zonas de convergência e desafios partilhados nos estudos de Eliseo Verón sobre a construção social do sentido
}

\author{
Claudiane Carvalho \\ Universidade Federal da Bahia, Salvador, BA, Brasil \\ ORCID: https://orcid.org/0000-0002-5000-1074
}

\begin{abstract}
Resumo
Este artigo propõe apresentar, numa dimensão descritivoanalítica, a interlocução entre Comunicação e Semiótica, pelo viés da teoria da discursividade social de Eliseo Verón. Ao tratar o discurso como materialidade espaço-temporal do sentido, Verón propôs um aporte teórico-metodológico para o estudo dos produtos mediáticos a partir das perspectivas do signo em Charles Sanders Peirce e do conceito de enunciação. O texto indica, via estudo bibliográfico, que a Teoria dos Discursos Sociais abarca a investigação dos efeitos de sentido nas enunciações mediáticas, superando as abordagens mecanicistas. Aponta, por fim, que, numa visada veroniana, Comunicação e Semiótica partilham uma zona de interseção constituída pelas preocupações com a produção social de sentido e a construção da realidade. Nesse âmbito, as modalidades de circulação da atual sociedade mediatizada desenham perspectivas e desafios à interface entre ambas.
\end{abstract}

\section{Palavras-chave}

Comunicação. Semiótica. Discurso Social. Signo. Enunciação.

\section{Delimitando fronteiras ou reconhecendo membranas?}

Comunicação e Semiótica: para além de traçar as fronteiras, nosso esforço, neste texto, é reconhecer possíveis membranas entre esses dois territórios do saber ${ }^{1}$, ou seja, finas camadas identificadas pela permeabilidade, as quais facilitaram o intercâmbio de conceitos,

\footnotetext{
${ }^{1}$ Neste artigo, não entraremos na discussão sobre a definição da Comunicação e da Semiótica como ciências e disciplinas. Para tanto, ver Martino (2017); Santaella (1995).
} 
métodos, preocupações, entre outros, nos estudos realizados pelo semioticista Eliseo Verón para tratar da construção social do sentido, especialmente, nos discursos mediáticos.

Enquanto processo social de produção e partilha de sentido através da materialização simbólica, a Comunicação sempre existiu, mas sua problematização ocorre na modernidade (FRANÇA, 2001). Nesse período, observa-se com mais clareza a importância e a contribuição dos meios de Comunicação para a tessitura do sentido de atualidade. Além disso, os meios passam a ter um papel relevante nas organizações, práticas e relações sociais, possibilitando a renovação e o surgimento de novas linguagens (MARTINO, 2017; SANTAELLA, 2007). Nesse contexto, engendra-se o esforço para construir uma ciência que, segundo Boutaud e Verón (2007, p. 13), apropriou-se de um "pedaço do real" (os media), ou seja, das implicações dos meios de Comunicação nas relações sociais e na cultura (MARTINO, 2017).

Concomitantemente, a Semiótica também recebe um impulso maior e avança nas suas investigações ao longo do século XX. Se, numa visada mais imediata, a Semiótica é a ciência dos signos, a ciência geral de todas as linguagens, ela encontra, na proliferação dos processos comunicativos por suportes técnicos, um terreno fértil e um estímulo aos seus estudos. Afinal de contas, delimita como objeto de investigação todas as linguagens possíveis (verbais e não verbais), ou seja, “[...] tem por objeto o exame dos modos de constituição de todo e qualquer fenômeno como fenômeno de produção de significação e sentido" (SANTAELLA, 2007, p. 13).

Ao tratar a convergência entre Comunicação e Semiótica, Boutaud e Verón defendem, em Sémiotique ouverte: itinéraires sémiotiques en communication (2007), que é preciso ir além das perspectivas funcionalistas e mecanicistas, de abordagens enclausuradas nos significantes ou outras vertentes instrumentalizadoras, a fim de que os itinerários semióticos sejam orientados pelo horizonte da Comunicação. Por esse prisma, é necessário atentar-se às contribuições pragmáticas da linguagem e às dimensões sensíveis e simbólicas das situações de comunicação na dinâmica do sentido e do social, ou seja, é preciso considerar não apenas signos, mas processos.

Para Boutaud e Verón (2007, p. 23), a Comunicação, enquanto atividade simbólica, "é o teatro permanente dos signos". E a Semiótica, na árdua empreitada de descrever e compreender o universo dos signos, saiu em vantagem ao privilegiar o significado nos atos comunicativos. A Comunicação, por seu turno, progrediu em processos complexos, envolvendo as questões de imagem, identidade e as negociações entre as condições de 
produção e recepção para construção discursiva. Em suas respectivas jornadas, Comunicação e Semiótica se cruzaram em sinal de maturidade (BOUTAUD; VERÓN, 2007) e partilham uma vasta zona de interseção, constituída pelas preocupações com a produção social de sentido e a construção da realidade, uma vez que "todo ato discursivo no seio da comunicação mediática envolve elementos essenciais da sociedade e da cultura" (BOUTAUD; VERÓN, 2007, p. 19). É sobre essas convergências e partilhas entre Comunicação e Semiótica, pelo viés da discursividade social de Eliseo Verón, que nos debruçaremos a seguir. Para tanto, o texto apresenta, além dos elementos introdutórios e apontamentos conclusivos, duas partes fundantes. Na primeira, a construção do sentido, a aventura da semiose, é entendida como ponto de conexão entre comunicação e Semiótica, pois "o horizonte do signo sempre nos remete ao espaço simbólico da Comunicação" (BOUTAUD; VERÓN, 2017, p. 25). Aqui, são apresentadas, de forma panorâmica, as perspectivas binária e triádica do signo, elaboradas, respectivamente, por Ferdinand de Saussure e Charles Sanders Peirce. A abordagem peirceana é visualizada como profícua à compreensão da construção das representações que sustentam as relações e práticas sociais. Essa revisão de literatura é realizada pelo prisma da produção acadêmica de Verón que, ao desenvolver a Teoria dos Discursos Sociais, chama atenção para a dimensão espaço-temporal do sentido.

\section{Dos pontos de convergência ou zona de interseção: a aventura da semiose e a construção do sentido}

Seguindo a tradição dos lógicos antigos e medievais, John Locke, inspirado na etimologia grega da palavra (sêmeiotikê), definiu a Semiótica como a ciência geral dos signos. Charles Sanders Peirce, em sintonia com a concepção de Locke, concebeu a Semiótica como a teoria geral dos signos.

Charles S. Peirce (dos EUA), Ferdinand de Saussure (da Europa Ocidental) e autores como A. N. Viesse-Iovski e A. A. Potiebniá (da antiga União Soviética) dedicaram-se a construir os estudos modernos sobre o signo. Aqui, vamos fazer um enfoque em Saussure e Peirce, por estarem mais diretamente vinculados à fundação da semiologia e da Semiótica, respectivamente, e por realizarem as perspectivas binária e triádica da constituição do signo, cujos resultados reverberam, de forma expressiva, nos estudos em Comunicação. Nossa leitura será conduzida pelas reflexões do semioticista Eliseo Verón ao desenvolver a Teoria da Discursividade Social. 

a abordagem da língua como uma nomenclatura para compreendê-la enquanto um sistema, que pode ser pensado como parte geral do estudo dos signos, a semiologia. Nesse âmbito, a semiologia consiste na iniciativa de ir além do estudo do signo linguístico; entretanto, não o faz fora do terreno da linguística.

As principais abordagens teóricas de Saussure estão compiladas no livro Curso de Linguística Geral, publicado inicialmente em 1916, a partir dos escritos feitos por estudantes que participaram de seminários ministrados por ele em Genebra, no início do século XX. Nesta obra, são apresentadas as perspectivas binárias sobre língua (enquanto sistema, estrutura) e fala (como o uso, apropriação individual da língua, a linguagem em ação). 0 signo, nessa concepção binária, é o composto entre significante e significado. Por essa ótica, o significado é o conceito e o significante é a imagem acústica, a qualidade material do signo.

Saussure (2004) ressalta a arbitrariedade convencionada do signo, ou seja, o signo não pode ser mudado ao gosto individual porque a língua é uma bagagem cultural, transmitida de geração a geração. Além disso, afirma que a língua não pode ser mais que um sistema de valores puros, no qual cada signo toma consistência por sua relação de oposição a outro, exemplo de rua e nua.

A abordagem saussureana carrega fortes traços do positivismo (VERÓN, 1987) e apresenta-se calcada numa compreensão funcionalista e estruturalista do signo (ZECCHETTO, 2008):

A visão funcionalista trouxe consequências no nível do significante e do significado. No que diz respeito ao significante, os linguistas trabalham sobre as regras de produção, especialmente da escrita. Desenvolvem suas análises, a partir da passagem do som - fenômeno material - à imagem acústica desse som - fenômeno psíquico -, sem analisar a passagem em si de um a outro. Não refletem sobre a materialidade do sentido, uma vez que veem tanto a leitura como a escrita como duas posições indistintas.

No que tange ao significado, ao considerar o signo - durante sua produção - como entidade psíquica, possibilita uma separação da língua em relação ao mundo real. Estabelece-se, deste modo, uma autonomia da língua - fato social - da ordem do real - "universo referencial dos signos linguísticos". (ZECCHETTO, 2008, p. 251, grifos do autor) ${ }^{2}$.

\footnotetext{
2 Tradução nossa para: “La visión funcionalista trajo consecuencias en el nível del significante y del significado. En lo que hace al significante, los lingüistas trabajaban sobre lãs reglas de producción, especialmente de La escritura. Desarrollaban su análisis a partir del pesaje del sonido - fenómeno material -, a La imagem acústica de dicho sonido - fenómeno psíquico - sin analizar el pasaje en sí de uno a otro. No se planteaban La materialidad del sentido, sino que veían tanto la lectura como la escritura como dos posiciones indistintas.

En el ordem del significado, el considerar al signo - durante su producción - como entidad psíquica, posibilitó una separación de la lengua con respecto al mundo real. Se establece, de este modo, una autonomia de La lengua - hecho social del orden real - 'universo referencial de los signos lingüísticos'”.
} 
Essa concepção binária reflete-se em uma noção estática do signo, a qual traz à tona uma questão fundamental sobre a construção social da realidade. Para Eliseo Verón, essa dimensão consiste em uma lacuna na obra de Saussure que impossibilita o estudo dos fenômenos sociais referenciados nos sistemas de representação:

Como o modelo do signo só comporta dois termos, o pensamento sobre o sentido permaneceu condenado ao binarismo: duas ordens postas em relação, duas caras de uma mesma moeda. A consequência foi a emergência de uma questão fundamental: a da construção do real, posta em forma de sistemas de representações. (VERÓN, 1987, p. 100).

No intuito de abarcar os sistemas de representação e, assim, dar conta da construção do real nos processos de significação, Verón (1987) recorre à Teoria Geral do Signo, de Charles S. Peirce.

Ao mesmo tempo em que Peirce foi um cientista, foi também um filósofo, banhando a ciência de filosofia e fazendo o exercício de filosofar cientificamente. Tendo como base a Lógica, transitou por vários campos do saber e dedicou sua vida a buscar categorias universais.

Desde o despertar do seu interesse pela Lógica, Peirce a concebeu como nascendo, em sua completude, dentro do campo de uma teoria geral dos signos. Desse modo, a Semiótica peirceana é uma filosofia científica da linguagem (SANTAELLA, 2007) ou uma teoria sígnica do conhecimento (ZECCHETTO, 2008).

Para o cientista, só pela fenomenologia se pode ler o mundo como linguagem; e o fenômeno, grosso modo, é entendido como tudo aquilo que aparece à mente, correspondendo a algo real ou não (SANTAELLA, 2007). "Aquilo com que estamos lidando não é metafísica: é lógica, apenas. Portanto, não perguntamos o que realmente existe, apenas o que aparece a cada um de nós em todos os momentos de nossas vidas" (PEIRCE, 2008, p. 84). Dessa maneira, a Semiótica peirceana anda de mãos dadas com uma teoria da realidade. Ele almejou uma universalidade do pensamento que lhe permitisse a compreensão da totalidade do mundo, traçou categorias amplas, capazes de abarcar realidades conhecidas e por conhecer. "Sua perspectiva Semiótica tende a ser uma filosofia do conhecimento" (ZECCHETTO, 2008, p. 49). Em síntese, sustentou uma Semiótica do conhecimento, ou seja, costurou uma aliança com a filosofia para explicar e interpretar o conhecimento.

$\mathrm{Na}$ semiótica peirceana, a realidade pode ser compreendida a partir de três categorias que permitem dar alguma unidade àquilo que é complexo e múltiplo e chega a 
essas categorias através do exame atento do modo como os fenômenos aparecem à mente. A primeiridade, que seria a dimensão do acontecimento existencial, refere-se à experiência direta - simplesmente é. É o impacto das coisas do mundo em nós, é o sentimento, o novo, o espontâneo. "Seria algo que é aquilo que é sem referência a qualquer outra coisa dentro dele, ou fora dele, independente de toda força e de toda razão" (PEIRCE, 2008, p. 24, grifo do autor). Na tradução de Zecchetto, diz respeito à dimensão da "possibilidade de ser, real ou imaginário. É pura possibilidade, ainda indeterminada, todavia é a que permite depois a concretização de todos os seres. A primeiridade é o abstrato" (ZECCHETTO, 2008, p. 50). Ou seja, "é o elemento de Originalidade irresponsável, livre" (PEIRCE, 2008, p. 24). Para ficar mais claro, pensemos na brancura da nuvem, a qualidade da cor em geral, sem especificação, ou seja, a brancura sem relação direta com a nuvem ou qualquer outra coisa. A primeiridade é o reino do abstrato, a potencialidade de interpretação (poder ser), o pano de fundo sobre o qual as coisas tomam forma. Para Peirce (2008), a primeiridade é o modo de ser do que é tal como é, sem referência a nenhuma outra coisa. Ele introduz o termo "Ground" para indicar, desde o ponto de vista lógico, a primeiridade como o momento inicial do conhecimento. "Desde o ponto de vista metafísico, podemos conceber a primeiridade como o ser em geral, tudo que pode ser pensado e dito, aquilo pelo qual alguma coisa se manifesta enquanto ser, em sua inefabilidade antes de ser uma coisa concreta"3 (ZECCHETTO, 2008, p. 50).

A secundidade é uma categoria relacional, de conflito ("Struggle") de um fenômeno de primeiridade com outros, é calcada nas analogias - eu reconheço um terremoto, porque tenho referências do que seja um. Trata-se do fenômeno existente, da possibilidade realizada, do que foi concretizado na relação com o pano de fundo geral da primeiridade. "A atividade Semiótica é algo real e, em consequência, é um fenômeno de secundidade. 0 Segundo é, pois, sempre o fim, o elemento ocorrido, o causado" (ZECCHETTO, 2008, p. 50) ${ }^{4}$. A secundidade faz referência à exterioridade, ou melhor, ao choque com o externo, ao movimento de resistência. Para Peirce (2008, p. 23), não se pode fazer esforço onde "não sentimos resistência alguma, nenhuma reação. 0 sentido de esforço é um sentido de dois lados, revelando ao mesmo tempo algo interior e algo exterior".

A simbolização está sob os desígnios da terceira categoria peirceana - a terceiridade. Ela exibe validade lógica ao real e o ordena, é formada por leis que regem e regulam os

\footnotetext{
3 Tradução nossa para: "Desde el punto de vista metafísico, podemos concebir la primeridad como el ser em general, todo lo que puede ser pensado o dicho, aquello por lo cual alguna cosa se manifiesta em cuanto ser, em su inefabilidad antes de ser una cosa concreta"

4 Tradução nossa para: "La actividad Semiótica es algo real y, em consecuencia, es un fenómeno de secundidad. Lo Segundo es, peus, siempre el fin, el elemento ocurrido, lo causado".
} 
fenômenos. "A triplicidade intelectual, ou Mediação, é minha terceira categoria" (PEIRCE, 2008, p. 27). Na tentativa de destrinchar a terceira categoria, Zecchetto explica que "se trata, então, de uma 'interrelação' estabelecida com o terceiro termo, ou seja, a interconexão de dois fenômenos em direção a uma síntese, a alguma lei que a reja, ao que pode ocorrer se se estabelecem certas condições" (ZECCHETTO, 2008, p. 51)5. Aliás, a existência da semiose está condicionada ao regimento de um conjunto de leis e princípios. A terceiridade, portanto, promove a aliança da primeiridade com a secundidade. Na semiótica peirceana, a forma genuína da terceiridade é a relação triádica que existe entre o signo, seu objeto e o interpretante (pensamento interpretador), o qual também se torna signo, desenhando o caráter rizomático da interpretação. Para Peirce, o signo é uma classe de terceiro, é algo que sempre estabelece uma conexão entre um primeiro e um segundo. 0 signo, portanto, é triádico por natureza.

Figura 1 - 0 Signo triádico de Peirce

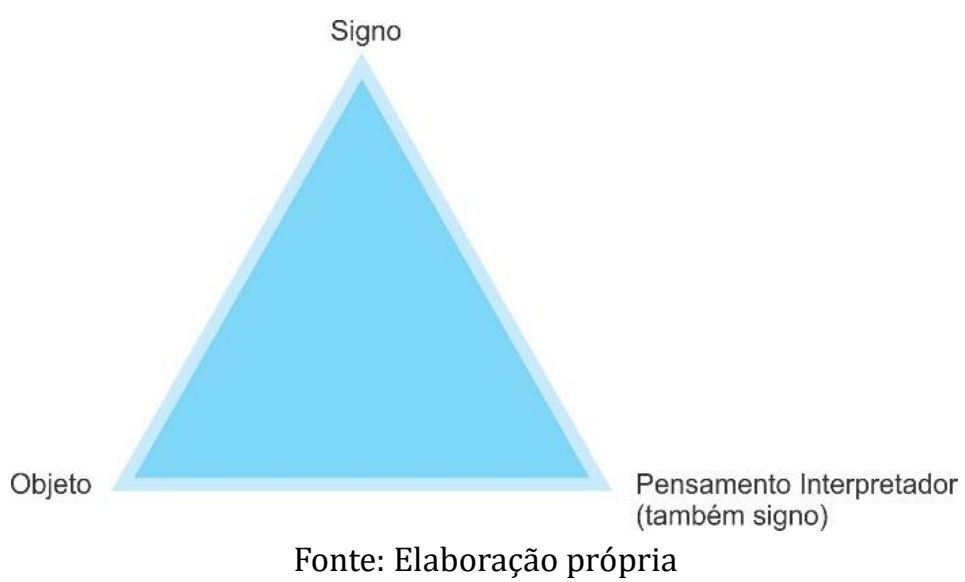

Numa tentativa de síntese do processo triádico de Peirce, Zecchetto (2008) mostra que o cientista norte-americano domina uma disposição para análise e interpretação da realidade, mediante o sistema de pensamento humano. A tríade "[...] pode descrever a situação global das coisas como qualidades (Primeiridade), ou em sua ação real (Secundidade), ou como entidade regida por leis e finalidades (Terceiridade), e sempre como uma experiência contínua e fluida" (ZECCHETTO, 2008, p. 54)6. Assim, a primeiridade é a chamada "qualidade de sentimento", a secundidade é a reação como elemento do próprio

\footnotetext{
5 Tradução nossa para: "Se trata, entonces, de la "interrelación” estabelecida com el tercer término, o sea, la interconexión de dos fenómenos em dirección a una síntesis, a alguna ley que la rige, o a lo que puede ocurrir si s estaclecen ciertas condiciones".

6 Tradução nossa para: "Éste puede describir la situación global de las cosas como cualidades (Primeridad), o en su acción real (Secundidad), o como entidades regidas por leyes y fines (Terceridad), y siempre como una experiencia continua y fluida"
} 
fenômeno e a terceiridade é a representação, também como elemento do fenômeno (PEIRCE, 2008).

Na Teoria Geral dos Signos de Peirce, Eliseo Verón encontrou respostas para o problema da representação - o signo é uma coisa que representa uma outra coisa, seu objeto. Nós só conhecemos o mundo porque, de alguma maneira, representamo-lo e só interpretamos essa representação em uma outra representação, o que Peirce denomina de interpretante da primeira. Eis, portanto, a explicação para a questão da representação e a possibilidade de construção do real pela linguagem.

Em outros termos, o signo implica sempre uma cadeia de representação ou de semiose; as representações, por sua vez, se manifestam tão somente por meio dos signos. Na semiose, nada está definido a priori, nem para sempre, ressaltando a função primordial do interpretante, o qual não se refere ao intérprete do signo, mas à complexidade do processo relacional entre signo e objeto que ocorre na mente do intérprete. Nesse âmbito, está a característica inefável da condição humana: para nós, tudo é signo, qualquer coisa que se produza na mente tem o caráter de signo - nossa relação com o mundo é sempre mediada.

Ainda nesse horizonte, a concepção de que a semiose é ilimitada, mas social e histórica amplia as abordagens mecanicistas das primeiras Teorias da Comunicação. 0 modelo do processo comunicativo, defendido por Harold Lasswell, na primeira metade do século passado, por exemplo, expõe uma visão linear, que não contempla a dimensão representativa. Segundo Machado (2001), a premissa que define a Semiótica como disciplina para o estudo da semiose assenta-se na fuga das perspectivas mecanicistas. A abordagem semiótica nos estudos da Comunicação prevê a produção de linguagem em ação na e da cultura; estar no mundo e com o mundo é precisar produzir sentido. Em outros termos, é pela semiose, pela possibilidade de representação, de interpretação, que se constrói o real histórico e socialmente, defende Verón (1987).

Por esse viés, explica-se por que a postura estruturalista, calcada em sistemas de signos arbitrários e imanentes, fraqueja diante da confrontação de sistemas básicos, a exemplo do linguístico, com as dimensões discursivas e enunciativas. Sob a perspectiva de que a produção do sentido é o fragmento da cadeia infinita da semiose, alargam-se os passos rumo a uma sociossemiótica. Nessa conjuntura, são contemplados os usos e apropriações sociais dos meios, a modelização dos contextos e as representações nas instâncias de produção e reconhecimento dos discursos. Ou seja, imprime-se à cadeia infinita da semiose o caráter histórico-social do sentido (VERÓN, 1987, 2004, 2013; BOUTAUD, VERÓN, 2007). 


\section{Do signo ao discurso social: a articulação entre Semiótica e Comunicação nos estudos de Eliseo Verón}

Resolvido o problema da representação e da construção social da realidade pelo prisma de semiose, Eliseo Verón buscou em Peirce a inspiração para construir um aporte teórico-metodológico que desse conta da análise de produtos mediáticos, cuja composição é feita de matérias significantes heterogêneas (texto, foto, ilustração, diagramação, áudio, vídeo etc.).

A necessidade de compreender a produção de sentidos a partir da comunicação mediatizada levou Verón a elaborar a Teoria dos Discursos Sociais, vinculando a noção de signo em Peirce à noção de discurso social, que foi forjada especialmente nos anos de 1980, dilatando a visão imanente da Linguística.

Para Braga (2008), a teoria dos discursos sociais se apresenta como uma dimensão translinguística ao recuperar dois problemas: a materialidade do sentido e a construção do real na rede de semiose. Vejamos, abaixo, como Verón propõe essa retomada, articulando a problemática dos discursos sociais com o modelo triádico peirceano:

Quadro 1 - Signo e discurso em perspectiva triádica

\begin{tabular}{|c|c|}
\hline Peirce & Teoria dos Discursos Sociais \\
\hline Interpretante & Operações \\
Signo & Discurso \\
Objeto & Representações \\
\hline
\end{tabular}

Fonte: Verón (1987, p. 124).

Segundo Verón, para entrar na rede semiótica, é preciso desenvolver uma análise com base em um fragmento da semiose, ou seja, um fragmento extraído do processo semiótico e presente em três posições funcionais: operações - discursos - representações (VERÓN, 1987; BRAGA, 2008). Por esse viés, entende-se que o discurso é a colocação do sentido no tempo e no espaço, uma vez que ocorre por meio de condições de produção, 
circulação e reconhecimento. Assim, a prática discursiva conclama sua dimensão sóciohistórica, temporal e simbólica, ancorada nas representações, as quais são mediadoras das relações em sociedade.

Na teoria da discursividade, os fenômenos sociais são entendidos como processos de produção de sentido. Desse modo, todo fenômeno social é um discurso e todo discurso é um fenômeno social (VERÓN, 1987, 2004). Analisar os discursos sociais esclarece, então, o estudo da construção do real, pois a realidade social é elaborada na semiose. Santaella corrobora esse ponto de vista:

\begin{abstract}
Considerando que todo fenômeno de cultura só funciona culturalmente porque é também um fenômeno de comunicação, e considerando-se que esses fenômenos só comunicam porque se estruturam como linguagem, pode-se concluir que todo e qualquer fato cultural, toda e qualquer atividade ou prática social constituem-se como práticas significantes, isto é, práticas de produção de linguagem e sentido. (SANTAELLA, 2007, p. 12).
\end{abstract}

Esses fenômenos, quando considerados numa sociedade mediatizada, têm na ambiência dos meios de comunicação um importante aspecto de transformação da sociedade e da cultura, alterando práticas e discursos sociais. Os meios de comunicação, portanto, constituem notáveis tecnologias e instituições para o desenvolvimento do processo de produção do sentido e construção do real.

Nesse contexto, o processo analítico tem o desafio de dar conta da materialidade do sentido nos produtos mediáticos, ou seja, abarcar a diversidade de matérias significantes. Por esse ângulo, Verón enfatiza que um discurso é uma configuração espaço temporal do sentido (VERÓN, 1987, 2004). Assim, tratar dessa configuração é atentar-se às condições de produção, de reconhecimento e à defasagem entre elas, ou seja, a circulação. A circulação reforça que a semiose social é uma rede significante infinita - a interpretação de um discurso solicita sempre outro discurso. E o processo analítico, vale sublinhar, sempre opera um corte, uma ruptura, extrai um fragmento da rede.

$\mathrm{Na}$ abordagem veroniana, todo discurso se relaciona a partir de determinadas regras, tanto nas suas condições de produção como em suas condições de reconhecimento. Essas regras compõem o que Verón chama de gramáticas de produção e de reconhecimento, cujas operações deixam pistas (rastros) na superfície discursiva. "As regras apresentadas nas gramáticas expressam 'operações de atribuição de sentidos nas matérias significantes'. 
Estas operações podem ser reconstruídas a partir de marcas presentes na superfície das ditas matérias." (BRAGA, 2008, p. 260).

Os estudos de Verón refutam os vieses imanentes ao prezarem pela articulação entre o intradiscursivo e o extradiscursivo, isto é, a relação entre as condições de produção e de reconhecimento. Abarcar essa relação é ocupar-se da enunciação (VERÓN 1983a, 1983b).

Da linguística de Benveniste à Teoria dos Discursos Sociais de Verón, o conceito de enunciação desenha um percurso que propõe reparar a fissura entre os estudos do texto e da recepção, apontando na direção de que os sentidos são construídos na defasagem ou na relação entre as condições de produção e reconhecimento. Em outros termos, o campo dos efeitos de sentido é forjado de acordo com as modalidades e a natureza da circulação. Essa abordagem, entretanto, surge como o resultado de um longo percurso, que se inicia com a compreensão do texto enquanto processo (CULIOLI et al, 1992).

Atendendo à proposta de conceber o uso da linguagem em contextos, Émile Benveniste, Oswald Ducrot e Antoine Culioli, por exemplo, dedicaram-se à teoria da enunciação francesa, suplantando, em abordagens e proporções distintas, as perspectivas mais imanentes. "Na enunciação, nós consideramos sucessivamente o próprio ato, as situações onde ele se realiza e os instrumentos da sua efetivação" (BENVENISTE, 1974, p. 81). A enunciação configura-se, então, como um trabalho relacional, à mercê de um feixe de situações. É o "[...] acontecimento constituído pela aparição de um enunciado" (DUCROT, 1987, p. 179). Numa concepção discursiva, não há produção de sentido sem enunciação, uma vez que esta é o "acontecimento em um tipo de contexto e apreendido na multiplicidade de suas dimensões sociais e psicológicas" (CHARAUDEAU; MAINGUENEAU, 2004, p. 193).

Irene Machado (2001) defende que onde há enunciação, há exercício de análise semiótica. Desse modo, como comprova a Teoria dos Discursos Sociais, os estudos das enunciações mediáticas solicitam um aporte teórico-metodológico da Semiótica. Em tempo, Verón distingue dois níveis de funcionamento de qualquer discurso: nível do enunciado (do dito), nível da enunciação (dos modos de dizer). Pela enunciação, o enunciador constrói um lugar para si, posiciona, de alguma maneira, o coenunciador, propondo entre ambos um tipo de relação.

Enfrentar a heterogeneidade dos discursos sociais conclama, aos olhos de Verón, uma dupla condição: 1) evitar a ilusão da unidade da consciência subjetiva, que faz desaparecer o social, e 2) resistir à tentação de reificar o sistema, que ignora a complexidade 
dinâmica da semiose (VERÓN, 2013, p. 119). No esforço de não cair nessa dupla armação, o semioticista empenhou-se, ao longo da sua carreira, a estudar como as modalidades do dizer constroem os dispositivos de enunciação, chamados de contrato de leitura ${ }^{7}$ (VERÓN, 1985, 2004).

No contrato de leitura, apresenta-se um enunciador que propõe um lugar a um “destinatário" (VERÓN, 1985, 2004). A análise semiológica do contrato consiste em destacar e descrever as operações que, no discurso do suporte, determinam a posição do enunciador e, consequentemente, a do coenunciador. Nesse ponto de vista, analisar o dispositivo de enunciação é analisar as condições de produção inscritas na materialidade discursiva ${ }^{8}$, ou seja, a relação proposta entre enunciador e coenunciador, o posicionamento discursivo do suporte.

A noção de contrato de leitura diz respeito ao vínculo, desnível, zonas de contato ou articulações ${ }^{9}$ entre as condições de produção e de reconhecimento, ou seja, às condições de circulação, cujas modalidades passaram por profundas transformações nas últimas décadas.

0 advento da internet e da web, da tecnologia móvel e das mídias digitais mudou as condições de produção dos discursos midiáticos e, consequentemente, os modos de dizer. Uma amplificação no grau de autonomia e persistência dos discursos no tempo e no espaço e a revolução do acesso motivaram alterações nas relações entre a produção e o reconhecimento. Dito de outra forma, novas modalidades de circulação estão sendo gestadas, o que implica mudanças nos dispositivos da enunciação (FAUSTO NETO, 2008, 2010). Face a isso, precisaremos transitar as pontes visíveis e invisíveis entre Semiótica e Comunicação, constituídas, ao longo do tempo, pela "abertura" de ambas para pesquisar as complexidades, os processos, os dispositivos, as questões de mediação, de sentido, de interpretação, entre outros (BOUTAUD; VERÓN, 2007). Pontes que, num movimento de reciprocidade e reiteração, simultaneamente, constituem e são constituídas pela teoria da discursividade social, proposta por Verón.

\footnotetext{
7 Desde a década de 1980, quando o "contrato de leitura” teve maior penetração no campo da Comunicação, a noção foi adaptada à análise de outros suportes, além dos impressos. Ver produções do Centro de Estudo e Pesquisa em Análise do Discurso e Mídia, no PÓSCOM/UFBA.

8 Eliseo Verón sempre defendeu a articulação entre as análises semiológicas e os estudos sociológicos e empíricos de recepção. Para ele, a análise dos dispositivos de enunciação compreende a análise da produção, mas o contrato se cumpre, mais ou menos bem, no leitor, ou seja, no reconhecimento.

9 Termos atenuantes à noção de vínculo entre produção e recepção, originalmente proposta por Verón. As expressões buscam atender às mudanças nas condições circulação, patrocinadas pelas novas tecnologias e meios de comunicação.
} 


\section{Notas conclusivas: perspectivas e desafios aos estudos na interface entre Semiótica e Comunicação}

A circulação dos discursos em dispositivos materiais, ao longo do tempo, expandiu a comunicação no tempo, no espaço e nas modalidades (HJARVARD, 2014). Esse fenômeno, denominado de mediatização ${ }^{10}$, acarretou na autonomia de emissores e receptores em relação ao discurso, a persistência do discurso no tempo e provocou a revolução do acesso, trazendo à cena a importância de compreender a circulação das mensagens na sociedade contemporânea (VERÓN, 2013, 2014; FAUSTO NETO, 2017, 2018).

A circulação não deixa traços na superfície discursiva, materializa-se no desnível, na diferença entre a produção e os efeitos de sentido, ou seja, na defasagem, num dado momento, entre as condições de produção do discurso e a leitura feita pela recepção (VERÓN, 2004).

As condições de circulação, por sua vez, estão ligadas ao suporte materialtecnológico e à dimensão temporal. No primeiro aspecto, a circulação é diretamente afetada pelas condições técnicas e tecnologias da sociedade em determinados momentos. Já o enfoque temporal remete à história social dos discursos (VERÓN, 2004).

Para Verón, apesar de não manifestar traços no discurso, a circulação é responsável pela dinâmica do modelo: "designa o modo como o trabalho social de investimento de sentido nas matérias significantes se transforma no tempo" (VERÓN, 2004, p. 54). Essa observação só ratifica a ideia de que, ao mudar as condições de produção, mudam-se as práticas discursivas e as modalidades do dizer, os dispositivos da enunciação.

A abordagem da circulação dos discursos no seio da sociedade demanda, na visão de Boutaud e Verón (2007), relações cúmplices entre Semiótica e Comunicação que articulam o sensível e o social em busca de uma espécie de antropologia dos nossos modos de experiência do signo e do sentido. Para tanto, ao elaborar a teoria da discursividade social, Verón $(1985,1987)$ propõe uma "semiótica aberta", rompendo com as perspectivas estruturalistas e mecanicistas para se alinhar às pesquisas capazes de comportar "a modelização dos contextos, a esquematização do funcionamento dos dispositivos mediáticos e a análise das configurações de representações que definem as condições da recepção dos discursos" (BOUTAUD; VERÓN, 2007, p. 18).

10 Mais sobre mediatização em: Lundby (2009, 2014); Hjarvard (2013); Verón (1994, 1995). 
Eliseo Verón, em especial, defende a semiótica operacional como ciência social, ou seja, uma socios semiótica, pois seu objeto é a circulação dos discursos no seio das sociedades. Com base na dinamicidade do conceito de signo em Peirce que remete à dimensão de processo, Verón propõe a transformação das possíveis fronteiras da Semiótica em membranas permeáveis ao antropológico e ao sociológico, disponibilizando, assim, aporte teórico-metodológico para um novo cenário sociotecnológico, ou seja, para uma paisagem mediática, na qual a internet tem provocado novas condições de acesso à discursividade mediática, acarretando transformações inéditas nas condições de circulação. Os diferentes usos da internet vêm alterando o acesso ao conhecimento e à cultura, a relação com o outro e o vínculo social com as instituições (VERÓN, 2013, p. 280-281). No que tange à produção social do sentido, "os processos de circulação são o novo campo de batalha, e essa guerra apenas começou" (VERÓN, 2013, p.282).

Se o aporte teórico-metodológico, proposto por Verón, pode oferecer um chão e as balizas ao estudo das modalidades de circulação do discurso no tecido social é porque ele é desenhado na perspectiva de que Semiótica e Comunicação, em certa medida, caminharam para a convergência. As trajetórias de ambas para abordar as complexidades da produção do sentido se cruzaram em pelo menos três dimensões: epistemológica, metodológica e operacional.

No plano epistemológico, Boutaud e Verón (2007) observam que os avanços pragmáticos e simbólicos da Comunicação - notados na valorização dos sujeitos da enunciação e dos efeitos de sentido - unem-se e acompanham o movimento da Semiótica ao considerar a ancoragem social do discurso (sociossemiótica) e as instâncias de enunciação em contexto (semiopragmática). Desse modo, Semiótica e Comunicação se encontram ao abarcarem, nos processos de significação, o polissensorial ou sinestésico, a multimodalidade (verbal, visual, som, espaço-temporal etc.) e plurissemiótica (discurso, objetos, espaços, práticas etc.).

No que tange ao nível metodológico, todas as formas de Comunicação (objetos, discurso, espaços, relações etc.) "colocam à prova" a Semiótica (FLOCH, 1990). Em contrapartida, a Semiótica "permite analisar metodicamente os 'efeitos de sentido' vinculados aos processos complexos e simbólicos da Comunicação"11 (BOUTAUD; VERÓN, 2007). Atinente à dimensão operacional, sustenta-se a postura de ir além do conceito de

\footnotetext{
11 Tradução nossa para: "permet d’analyser, avec méthode, les 'effets de sens” liés aux processos complexes et symboliques de la communication".
} 
signo para pensar nos usos e contextos. Uma Semiótica operacional ou "aberta" preza pela articulação entre o sensível, o estético e o ético, sendo o sensível um dos pontos mais avançados no diálogo entre Semiótica e Comunicação (BOUTAUD; VERÓN, 2007). Aqui, JeanMarie Floch (1990) assegura que não se trata de buscar aplicações, mas "qualificar" e adquirir competências para compreender melhor as diversas formas de significação e as condições gerais de produção, recepção e circulação dos sentidos.

A simetria entre Semiótica e Comunicação, engendrada na teoria da discursividade social de Verón, aponta um caminho ou, pelo menos, oferece pistas para analisar a produção de sentido num cenário de advento e consolidação de tecnologias que expandem a comunicação no tempo, no espaço e na modalidade, implicando transformações expressivas nas condições de circulação do discurso social (HJARVARD, 2014; VERÓN, 2014). Os fenômenos mediáticos que comportam a mediatização contemporânea têm alterado as formas sociais de contato em dimensões, nas quais a circulação tem atividade estruturante: as relações entre os indivíduos e o conhecimento, os indivíduos entre si e os indivíduos e as instituições (VERÓN, 2013, 2014).

Essas novas configurações relacionais alteram a natureza dos elos e dos vínculos na sociedade, mudam práticas e discursos sociais e desenham, portanto, um horizonte desafiador aos estudos da Comunicação e da Semiótica: abordar o processo social de produção de sentido e construção da realidade, a partir das condições de circulação dos discursos sociais. Esse desafio não se agiganta diante da percepção de Boutaud e Verón (2007, p. 25) de que a Semiótica e a Comunicação seguiram caminhos "na direção de variáveis intersubjetivas, contextuais, sociais e pragmáticas". Se "o horizonte do signo sempre nos remete ao espaço simbólico da comunicação", ao longo do tempo, esse movimento de abertura e de determinação recíproca entre Semiótica e Comunicação se solidificaram, especialmente na abordagem dos discursos mediáticos pelo prisma da noção de discurso social, ou seja, da materialização do sentido no tempo e no espaço. Dessa forma, temos o bônus e ônus do legado:

As perspectivas são, portanto, numerosas e o debate está aberto, da teoria à prática, da contribuição científica à contribuição social. Como pudemos observar, o social "volta" sob a solicitação de efeitos de sentido e processos que não dizem mais respeito a uma semiótica e a uma comunicação presas a padrões reais ou supostos, mas reconhecidas em suas respectivas competências e sua aliança objetiva. Para além das mensagens, trata-se de 
compor com usos; para além dos signos, deve-se considerar o sentido. (BOUTAUD; VERÓN, 2007, p. 46) ${ }^{12}$.

Ao esgarçar os limites da linguística para considerar uma reflexão fenomenológica sobre os signos, a Semiótica abre-se ao social. Ao rever os modelos mecanicistas e transmissionistas face aos estudos de recepção e identidade, a Comunicação também considera a produção de sentido em contextos, molduras sócio-históricas. Essa confluência desembocou na sociossemiótica, uma perspectiva operacional e aberta da Semiótica, que tem no sensível um ponto avançado da conexão, conforme frisado anteriormente. Por esse prisma, abandona-se o dualismo entre inteligível e sensível, para se investir na dinâmica ternária entre estésico/sinestésico, ético (modos de agir) e estético (emergência da forma) (BOUTAUD; VERÓN, 2007). Eis as condições para se refletir sobre: quais interpretantes são acionados para se ler os fluxos de circulação e a produção enunciativa da sociedade mediatizada?

Parece indiscutível que a aceleração do tempo histórico tem sido uma das dimensões mais manifestas da história da mediatização, especialmente nas modalidades contemporâneas de circulação. No curso da história, mais uma vez, portanto, Comunicação e Semiótica, pelo viés da discursividade social, precisam ampliar suas zonas de interseção e aumentar o grau de permeabilidade de suas membranas, nas dimensões ontológicas, epistemológicas e metodológicas, para construir aportes teórico-metodológicos que deem conta da complexidade da produção de sentido nos fluxos da circulação.

\section{Referências}

BENVENISTE, Émile. Problèmes de linguistique générale. 2. Paris: Gallimard, 1974.

BOUTAUD, Jean-Jacques.; VERON, Eliseo. Sémiotique ouverte: itinéraires sémiotiques en communication. Paris: Lavoisier, 2007.

BRAGA, María Laura. Eliseo Verón n. 1935. In.: ZECHETTO, Victorino (org.). Seis Semiólogos en busca del lector. Buenos Aires: La Crujía, 2008. p. 241-283.

CHARAUDEAU, Patrick; MAINGUENEAU, Dominique. Dicionário de análise do discurso. Coord. da Trad. Fabiana Komesu São Paulo: Contexto, 2004.

\footnotetext{
12 Tradução nossa para: "Les perspectives sont donc nombreuses et le débat largement ouvert, de la théorie à la pratique, de la contribution scientifique à la contribution sociale. Comme on a pu l'observer, le social 'fait retour' sous la solicitation d'effets de sens et de processus qui ne concernent plus une sémiotique et une communication, enfermées dans des schémas reels ou supposés, mais reconnues dans leurs compétences respectives et leur aliance objective. Au-delà des messages il s'agit de composer avec des usages, au-delà des signes voir du sens.
} 
CULIOLI, A. et al., La théorie de Antoine Culioli - ouvertures et incidentes. Paris: Ophrys, 1992.

DUCROT, Oswald. 0 dizer e o dito. Trad. Eduardo Guimarães. Campinas, SP: Pontes, 1987.

ECO, Umberto. Lector in fabula. São Paulo: Ed. Perspectiva, 2002.

FAUSTO NETO, Antonio; FERREIRA, Jairo; BRAGA, José Luiz; GOMES, Pedro. Midiatização e processos sociais na América Latina. São Paulo: Paulus, 2008.

FAUSTO NETO, Antonio. Trajetos do corpo de uma mulher. In: CASTRO, Paulo César (org.). Circulação Discursiva: entre produção e reconhecimento. Maceió, Alagoas: EDUFAL, 2017.

FAUSTO NETO, Antonio. Circulação: trajetos conceituais. Rizoma, Santa Cruz do Sul, v. 6, n. 2, p. 8, dezembro, 2018.

FERREIRA, Giovandro Marcus e ANDRADE, Ivanise Hilbig de. Percurso da reflexão sobre a mediatização nos estudos de Eliseo Verón. In: COLÓQUIO BRASIL-ARGENTINA DE CIÊNCIAS DA COMUNICAÇÃO, 5., 2015, Rio de Janeiro. Anais [...]. Rio de Janeiro, 2015.

FLOCH, Jean-Marie. Sémiotique, Marketing et Communication. Paris: PUF, 1990.

FRANÇA, Vera Veiga. O objeto da Comunicação/ A Comunicação do objeto. In: HOHLFELDT, A.; MARTINO, Luiz Cláudio.; FRANÇA, Vera Veiga (org.). Teorias da Comunicação: conceitos, escolas e tendências. Petrópolis: Vozes, 2001.

HJARVARD, Stig. A midiatização da cultura e da sociedade, Editora Unisinos, São Leopoldo, 2013.

HOHLFELDT, A.; MARTINO, Luiz Cláudio.; FRANÇA, Vera Veiga (org.). Teorias da Comunicação: conceitos, escolas e tendências. Petrópolis: Vozes, 2001.

LUNDBY, Knut (ed.). Mediatization: concept, changes, consequences. New York: Peter Lang, 2009.

LUNDBY, Knut (ed.). Mediatization of communication. Boston: De Gruyter, 2014. v. 21. (Handbooks of Communication Science)

HJARVARD, Stig. A midiatização da cultura e da sociedade. São Leopoldo: Editora Unisinos, 2013.

MACHADO, Irene. 0 ponto de vista semiótico. In: HOHLFELDT, A.; MARTINO, Luiz Cláudio.; FRANÇA, Vera Veiga (org.). Teorias da Comunicação: conceitos, escolas e tendências. Petrópolis: Vozes, 2001.

MARTINO, Luiz Cláudio. Escritos sobre Epistemologia da Comunicação. Porto Alegre: Sulina, 2017.

PEIRCE, Charles Sanders. Semiótica. 4 ed. São Paulo: Perspectiva, 2008. (Estudos, 46) 
SANTAELLA, Lúcia. 0 que é Semiótica. São Paulo: Brasiliense, 2007 (Coleção Primeiros Passos, 103)

SANTAELLA, Lúcia. A Teoria geral dos signos. São Paulo: Ática: 1995.

SAUSSURE, Ferdinand de. Curso de linguística geral. São Paulo: Cultrix, 2004.

VERÓN, Eliseo. Il est lá, je ele vois, il me parle. Communicationsn, Paris, n. 38, 1983b.

VERÓN, Eliseo. L'analyse du contrat de lecture: une nouvele methode pour lês études de positionnement des supports presse, Les Médias. Expériences, recherches actuelles, applications. Paris: IREP, 1985. p. 203-229.

VERÓN, Eliseo. Fragmentos de um tecido. São Leopoldo: Editora Unisinos, 2004.

VERÓN, Eliseo. La sémiosis sociale. Fragments d'une théorie de la discursivité. Paris: Presses Universitaires de Vincennes, 1987.

VERÓN, Eliseo. La semiosis social, 2: ideas, momentos, interpretantes. Buenos Aires: Paidós, 2013.

VERÓN, Eliseo. Teoria da midiatização: uma perspectiva semioantropológica e algumas de suas consequências. Matrizes, São Paulo, v. 8, n. 1, p. 13-191. jan./jun. 2014.

VERÓN, Eliseo. Mediatización, comunicación política y mutaciones de la democracia. Semiosfera, [s.l.], n. 2, p. 5-36, 1994.

VERÓN, Eliseo. Médiatisation du politique. Stratégies, acteurs et construction des collectifs. Hermès, [s.l.], v. 3, n. 17-18, p. 201-214, 1995.

VERÓN, Eliseo. Quand lire c'est faire: l'énonciation das le discours de la presse écrite. Semiotique II. Paris: IREP, 1983a, p. 33-56.

WOLF, Mauro. Teorias da Comunicação de massa. São Paulo: Martins Fontes, 2003.

ZECCHETTO, Victorino. Charles Sanders Peirce 1839/1914. In: ZECHETTO, Victorino (org.). Seis Semiólogos en busca del lector. Buenos Aires: La Crujía, 2008. p.41-79.

\section{Communication and Semiotics: \\ zones of convergence and shared challenges in the study of social sense construction}

\footnotetext{
Abstract

This article proposes to present, in a descriptive-analytical dimension, the dialogue between Communication and Semiotics, through the bias of the theory of social discursivity of Eliseo Verón. By treating discourse as a spatiotemporal
} 
materiality of meaning, Verón proposed a theoretical and methodological approach to the study of media products from the perspective of the sign in Charles Sanders Peirce and the concept of enunciation. The text indicates, through bibliographic study, that the Theory of Social Discourses encompasses the investigation of the effects of meaning on media enunciations, surpassing mechanistic approaches. Finally, it points out that Communication and Semiotics share an intersection zone constituted by concerns with the social production of meaning and the construction of reality. In this context, the circulation modalities of the current mediatized society draw perspectives and challenges to the interface between them.

\section{Keywords}

Communication. Semiotics. Social Speech. Sign. Enunciation

\section{Autoria para correspondência}

Claudiane Carvalho

cauoliveira@yahoo.com.br

\section{Como citar}

CARVALHO, Claudiane. Comunicação e Semiótica: zonas de convergência e desafios partilhadosnos estudos de Eliseo Verón sobre a construção social do sentido. Intexto, Porto Alegre, n. 52, e-98958, jan./dez. 2021. DOI: http://dx.doi.org/10.19132/1807-8583202152.98958

Recebido em 13/12/2019

Aceito em 09/03/2021

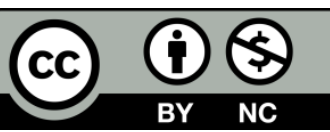

